\title{
Application of the "covered-stent-in-uncovered- stent" technique for easy and safe removal of embedded biliary uncovered SEMS with tissue ingrowth
}

Removal of embedded biliary uncovered self-expandable metal stents (uSEMS) is regarded as difficult or even impossible when the duration of indwell exceeds a couple of weeks, because of the ingrowth of tissue [1-3]. The presence of diffuse and severe ingrowth is the main feature limiting SEMS removal [1]. In the esophagus, placement of a self-expanding plastic stent (SEPS) inside the SEMS has been shown to induce pressure necrosis of this tissue hyperplasia, allowing subsequent removal of the stent [4]. We applied this technique in a 58-year-old patient with a history of alcohol abuse, obstructive jaundice, and suspected malignancy, in whom an uSEMS $10 \mathrm{~mm}$ wide and $6 \mathrm{~cm}$ long (Wallflex; Boston Scientific, Natick, Massachusetts, USA) had been mistakenly inserted more than 1 year before. The patient had experienced recurrent cholangitis due to stent obstruction caused by tissue ingrowth. Stent removal was therefore considered, but was unsuccessful using conventional maneuvers. A covered SEMS (Wallflex) was then placed inside the uSEMS ( $\bullet$ Figs. 1, 2).

The patient developed acute cholecystitis and a liver abscess, needing percutaneous drainage and prolonged antibiotherapy. Four weeks later, after resolution of the sepsis, removal of both stents was reattempted but failed due to persistent tissue ingrowth. A new covered SEMS was inserted for another 4-week period. Endoscopic retrograde cholangiopancreatography showed spontaneous migration of the covered stent and disappearance of the tissue hyperplasia, except at the distal end of the metal stent ( $\bullet$ Fig. 3 ).

Removal of the uncovered stent was, however, easy using a rat-tooth forceps (๑ Fig. 4).

Damage to the bile duct was checked using SpyGlass (Boston Scientific), which showed permeability and no residual stricture ( $\bullet$ Fig. 5 ).

Removal of biliary uncovered SEMS is less successful than removal of covered stents ( 0 - 38\% vs. $92 \%$ ). We previously reported

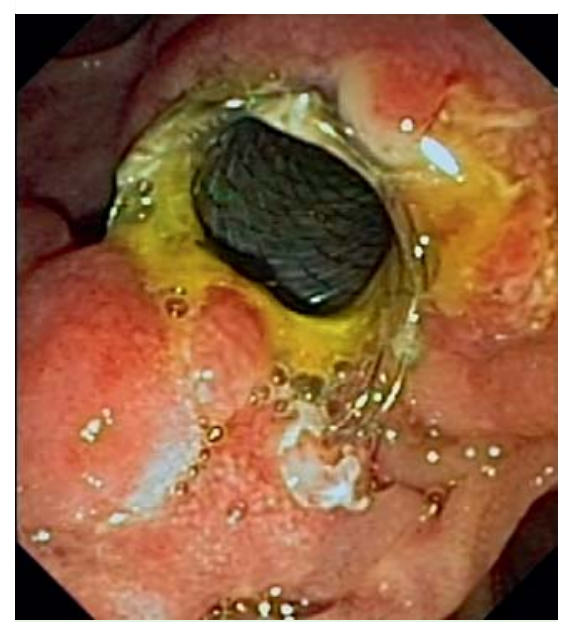

Fig. 1 Endoscopic view of the placement of a covered self-expandable metallic stent (SEMS) inside the uncovered SEMS.

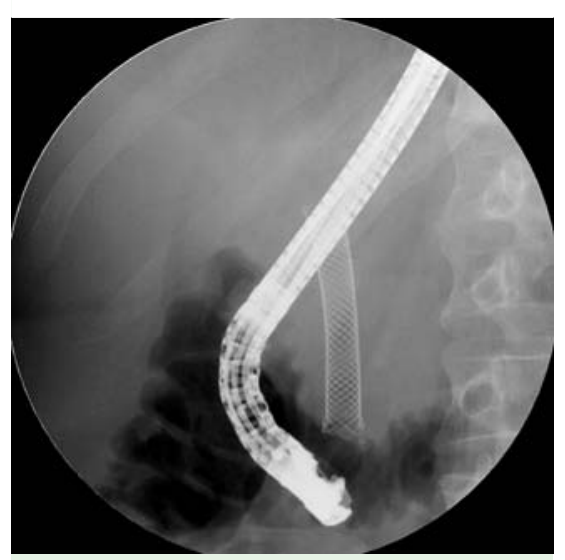

Fig. 2 Fluoroscopic view of both covered and uncovered stents in the common bile duct.

on piecemeal extraction of double uncovered Wallstents in a laborious procedure [5]. More recently we applied the "covered-stent-in-uncovered-stent" technique described for removal of esophageal SEMS in the biliary tree and showed that a period of $6-8$ weeks might be appropriate for successful and less time-consuming removal.

Competing interests: None

Endoscopy_UCTN_Code_TTT_1AR_2AZ

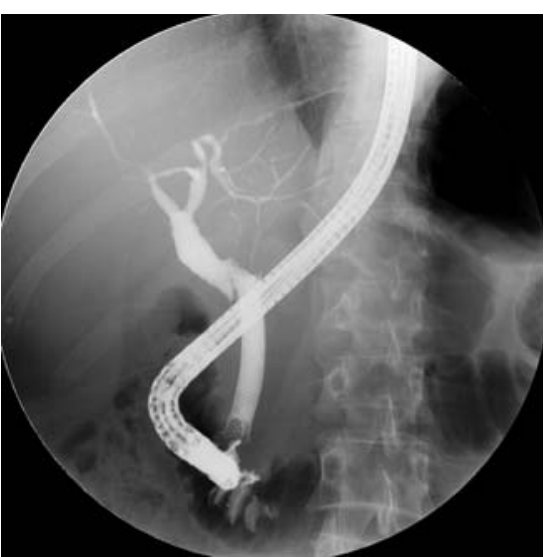

Fig. 3 Disappearance of tissue ingrowth shown by common bile duct opacification.

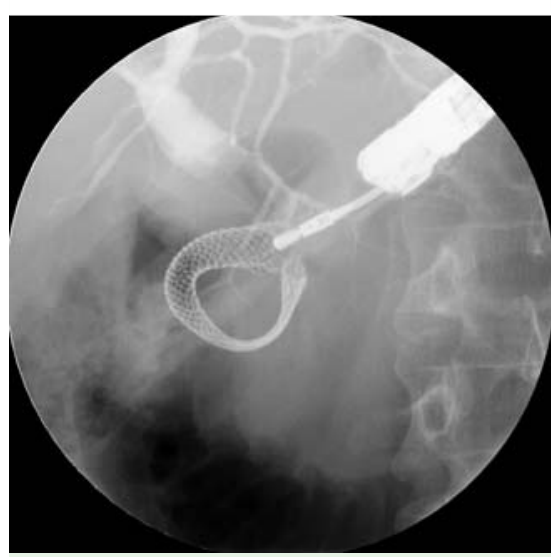

Fig. 4 Extraction of the uncovered SEMS with a rat-tooth forceps.

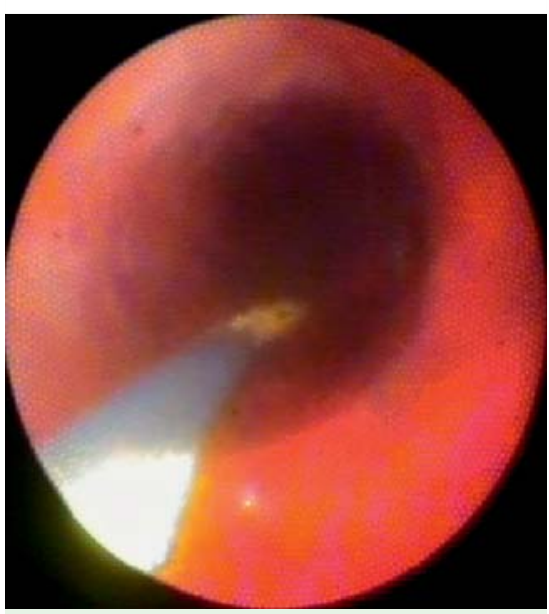

Fig. 5 SpyGlass cholangioscopy showing permeability of the common bile duct and absence of damage after removal of the stent. 
F. J. Arias Dachary ${ }^{1}$, C. Chioccioli ${ }^{2}$, P. H. Deprez ${ }^{1}$

1 Gastroenterology Department, Cliniques Universitaires Saint-Luc, Université Catholique de Louvain, Brussels, Belgium

2 Service de Gastro-entérologie, Clinique St-Jean, Brussels, Belgium

\section{References}

1 Familiari P, Bulajic M, Mutignani M et al. Endoscopic removal of malfunctioning biliary self-expandable metallic stents. Gastrointest Endosc 2005; 62: 903-910

2 Stainier L, Hubert C, Jouret $M$ et al. Self-expanding metallic stents in benign postoperative biliary strictures: a difficult surgical obstacle? Hepatogastroenterology 2007; 54: 999- 1003

3 Shin HP, Kim MH, Jung SW et al. Endoscopic removal of biliary self-expandable metallic stents: a prospective study. Endoscopy 2006; 38: $1250-1255$

4 Eisendrath P, Cremer M, Himpens J et al. Endotherapy including temporary stenting of fistulas of the upper gastrointestinal tract after laparoscopic bariatric surgery. Endoscopy 2007; 39: 625-630

5 Lahlal M, Gigot JF, Annet L, Deprez PH. Successful endoscopic extraction of a double uncovered expandable metal stent. Endoscopy 2009; 41 Suppl 2: E98 - E99
Bibliography

DOI $10.1055 / \mathrm{s}-0030-1255792$

Endoscopy 2010; 42: E304 -E305

(c) Georg Thieme Verlag KG Stuttgart · New York . ISSN 0013-726X

\section{Corresponding author}

\section{P. H. Deprez, MD, PhD}

Gastroenterology

Cliniques Universitaires Saint-Luc

Université Catholique de Louvain

Av. Hippocrate 10

1200 Brussels

Belgium

Fax: +32-2-7648927

pdeprez@uclouvain.be 